
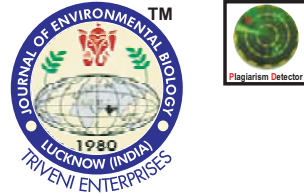

\title{
Gene expression profiling and expression analysis of freshwater shrimp (Neocaridina denticulata denticulata) using expressed sequence tags and short-term exposure to copper
}

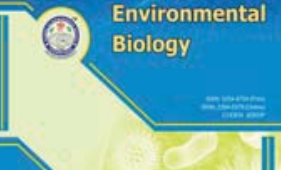

\section{Authors Info}

N. Y. Kim', E. J. Jeon', S. H. Jung', S. J. Ahn', M. A. Park and J.S. Seo ${ }^{3 *}$

${ }^{1}$ Pathology Research Division, National Institute of Fisheries Science (NIFS), Busan-46083, Korea

${ }^{2}$ Fisheries R\&D Management Center, Korea Institute of Marine Science \& Technology Promotion (KIMST), Seoul-06775, Korea

${ }^{3}$ Aquatic Disease Control Division, National Institute of Fisheries Science (NIFS), Busan-46083, Korea

${ }^{*}$ Corresponding Author Email : pharm001@korea.kr

Key words

Biomarker

Copper

Expressed sequence tags Neocaridina denticulata

Transcriptome

Publication Info

Paper received : 28.11 .2015 Revised received : 23.05.2016

Re-revised received : 30.06 .2016 Accepted : 05.07.2016

\section{Abstract}

Aim : The aim of the current study was to investigate environmental potential biomonitoring marker to exposure the copperfrom freshwater shrimp using expressed sequence tag (EST) analysis.

Methodology : The freshwater shrimp was collected from Lake Chang Pyung, South Korea and made cDNA libraries from whole body. To analyze expression patterns of putative biomarkersaccording to the individuals'exposure to copper in a time-and concentration-dependentmanners, Quantitative PCR (qPCR) was conducted.

Results : The expression levels of 9 potential biomarkers for heavy metal exposure including arginine kinase, acheron, cytochrome c oxidase subunit I, metallothionein, methylene tetrahydrofolatereductase, glutathione peroxidase, cathepsin $\mathrm{L}$, cathepsin $\mathrm{A}$ and $\mathrm{Cu} / \mathrm{Zn}$ superoxide dismutase genes were upregulated 1-24 hr post-exposure to copper, in an exposure time- and/or dose-dependent manner. Furthermore, the discovery of genes that relate to heavy metal exposure and immune defense enables us to investigate the toxicity mechanisms and ecological effects of heavy metal pollution.

Interpretation : This study contributes to the identification of numerous EST clones that can be applied to further clarify the genetics and biomonitoring markers of freshwater shrimp.

\section{Environmental biomonitoring marker}

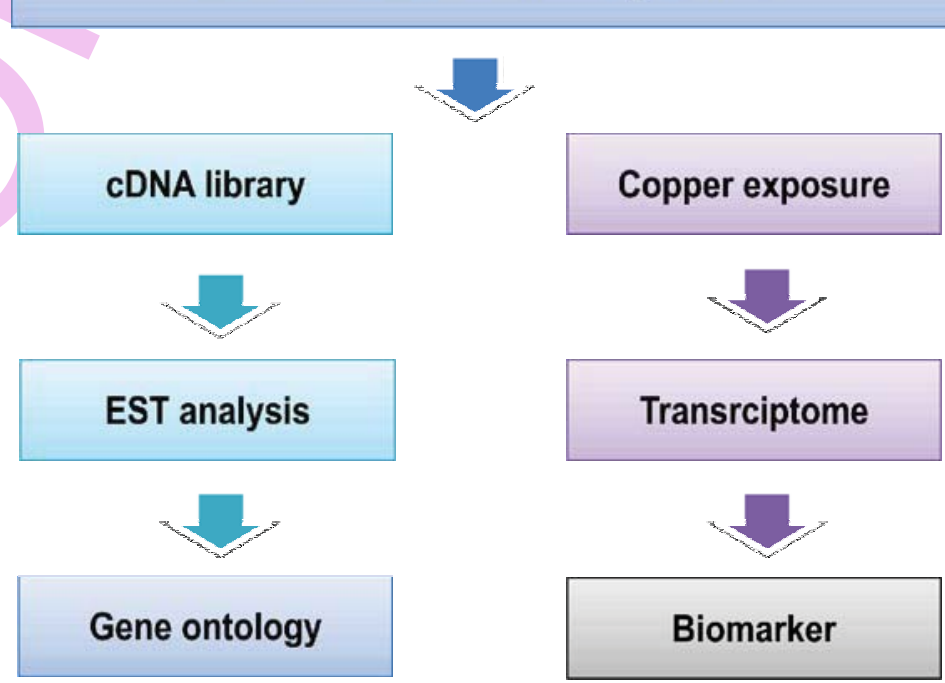




\section{Introduction}

In many countries, freshwater shrimp cultivation is an economically important component of aquaculture industry. Freshwater shrimp has commercial value as fishing bait as food. In addition, inappropriate pond management or any event that reduce water quality can induce disease outbreaks among the shrimps and thus, decrease production (Chamberlain, 1997). Changes in certain environment factors, such as amount of dissolved oxygen, salinity and temperature, can affect the environment and increase the susceptibility of shrimp to disease (Lightner, 1996).

Other studies have reported that both heavy metals released from sediments and contamination of shrimp farms by pesticides and pollutants from agriculture or industrial activities may decrease the resistance of these shrimp to disease. Heavy metal pollution and eutrophication are common problems in freshwater ecosystems throughout the industrialized world.

Heavy metals ultimately enter aquatic systems and may cause short-term and long-term negative biological effects. Among these pollutants, copper is a widespread contaminant in coastal and estuarine ecosystems (Wright, 1986; Arun Kumar and Achyuthan, 2007; Munari and Mistri, 2007). Sources of copper in aquatic habitats include antifouling paint and algaecides, runoff of agricultural fertilizers, mine drainage, waste water from metal smelting, and atmospheric fallout from fossil fuel combustion and refuse incineration (IPCS, 1998). Bioavailability of copper is largely dependent on the concentration of free divalent cation but bioaccumulation of copper can also be influenced by salinity (Bidwell and Gorrie, 2006). Copper is an essential trace element that functions, as a cofactor for enzymes involved in oxidation/reduction reactions. Copper is also a component of hemocyanin, the molecule responsible for oxygen transport in the hemolymph of arthropods. However, copper can have toxic effects at concentrations above those that are essential (Bradl, 2005).

Mechanisms of copper toxicity include binding to proteins and DNA at sulfhydryl, carboxylate, and imidazole sites and catalyzing the production of reactive oxygen species. Copper can directly impair protein function, cause peroxidation of lipids, damage DNA and organelles, and ATP depletion (Stohs and Bagchi, 1995). The toxic effects of copper may reduce survival, induce behavioral alterations and delay development in aquatic invertebrates (Lodhi et al., 2006). Copper may also inhibit reproduction in aquatic invertebrates by delaying sexual maturation, reducing fertilization success (Reichelt-Brushett and Michalek-Wagner, 2005), decreasing fecundity (Garnacho et al., 2001), and reducing the proportion of reproductive females in a population.

In recent years, genomic approaches have been increasingly applied to study toxicology. Genomics helps in understanding the mechanisms that underlie the toxic effects of chemicals on the living tissues of various organisms. The approach may help to identify gene expression profiles that could serve as biomarkers of exposure to toxins (Calzolai et al., 2007). Until now, many investigators have used expressed sequence tags (ESTs) to screen potential biomarkers by analyzing expressed transcripts from bioindicator organisms of heavy metal pollution (Auslander et al., 2008; Wang et al., 2014; Cornu et al., 2017).

The freshwater shrimp (Neocaridina denticulata denticulata) inhabits lentic and lotic waters of the Indo-West Pacific, China, Japan, and Taiwan. Several characteristics make this species a good aquatic indicator for assessing environmental pollution: small size $(2-3 \mathrm{~cm})$, spontaneous interbreeding, and absence of metamorphosis stage during development (Mykles and Hui, 2015).

This is the first report for the profile of the freshwater shrimp transcriptome to investigate environmental potential biomonitoring marker to exposure the copper. We constructed a cDNA library using mRNA extracted from the whole bodies of freshwater shrimp for expressed sequence tag(EST) analysis. The results revealed valuable candidate genes that are potential biomonitoring markers.

\section{Materials and Methods}

Animals and sample preparation : A total of 10 freshwater shrimp were collected from the Lake Chang Pyung, Kunwigun, (an area with relatively clean-water), Gyung Sang Buk Do Province, South Korea, and were maintained in aerated natural lake water. In laboratory, the whole body of each specimen was rapidly frozen with liquid nitrogen and ground with a mortar and pestle.

cDNA library construction : Total RNA was isolated from the samples using Trizol reagent (Invitrogen, USA), and mRNA was purified from total RNA using an mRNA purification kit (Stratagene, USA). To construct a cDNA library, a directional $\lambda$ ZAP cDNA synthesis/Gigapack III gold cloning kit (Stratagene, USA) was used. The reverse transcription of mRNA for firststrand CDNA synthesis was primed from the poly-A tail using an oligo-dT linker primer containing an Xhol cloning site. Following second-strand synthesis, EcoRl linkers were ligated to the $5^{\prime}$ termini. The fractionated cDNAs (above $500 \mathrm{bp}$ ) were then precipitated and ligated to the ZAP Express vector (pBK-CMV). Primary library was produced by in vitro packaging of ligation product using a ZAP Express cDNA Gigapack III Gold cloning kit (Stratagene, USA)(Aniello et al., 1996). The library contained $5.2 \times 10^{5}$ plaque forming units. Mass excision was performed and the cDNA inserts from the amplified $\Lambda$ ZAP library were rescued as pBK-CMV phagemids in XLOLR Escherichia coli. Average insert size was determined by Alpha Digi-Doc analysis and compared with a standard $100 \mathrm{bp}$ Plus DNA ladder. The average insert size 
for library was $1.5 \mathrm{~kb}$.

Plasmid isolation and DNA sequencing : Independent colonies were picked randomly, inoculated into individual wells of 96 -well deep well plates containing $1 \mathrm{ml}$ of Luria Bertani media broth and incubated at $37^{\circ} \mathrm{C}$ for $18 \mathrm{hr}$. Plasmid DNAs was extracted using a Montage Plasmid Miniprep 96 Kit (Millipore, USA) according to the manufacturer's instructions. The CDNA inserts were sequenced once from the 5 ' end (T3 universal primer) of clones using a BigDye Terminator Sequencing Kit ver. 3.1 (Applied Biosystems, USA) and a 3730XL DNA Analyzer (Applied Biosystems, USA)(Martin et al., 2006).

Cleaning, annotation and clustering of ESTs : The ESTs obtained from Suppression subtractive hybridization clones were initially analyzed and annotated using Pipeline for EST Analysis Service (PESTAS), an automated EST analysis platform (unpublished, http://pestas.kribb.re.kr). In the present study, analysis was carried out in two steps. In step $1, N$. denticulata denticulata EST trace data were base-called using the program Phred with a Phred score of 13 (Ewing and Green, 1998). The sequences were then processed with the cross_match (http://www.phrap.org), RepeatMasker (http://www.repeat masker.org/) and SeqClean (http://compbio.dfci.harvard.edu/tgi/ software/) programs to filter out vector, repetitive element and mitochondrial DNA sequences. Trimmed sequences more than $100 \mathrm{bp}$ in length were clustered and assembled into unique sequences by TIGR Gene Indices clustering tools (TGICL) (Pertea et al., 2003) and CAP3 programs (Huang and Madan, 1999) using their default options. In step 2, to assign putative functions to EST, a BLASTX search of nonredundant (NR) protein database was performed at the National Center for Biotechnology Information (NCBI). Descriptions and sequence alignments were taken into account for the best hits with E-values below $1 \mathrm{e}^{-10}$ and at least $30 \%$ identity over 30 amino acids.

Gene ontology (GO) analysis : $G 0$ annotations were assigned using the program Blast2GO(cut-off value $<1 \mathrm{e}^{-10}$ ) (Conesa et al., 2005). BLASTX results were loaded into the program and the default settings were used to assign GO terms to all unique sequences. From these annotations, pie charts were made using $3^{\text {td }}$ level GO terms based on the biological process, molecular function and cellular component. In order to predict pathways in $N$. denticulata denticulata, we mined enzyme information was mined from the annotated results of the UniProtKB database (Schneider et al., 2009) that contained Enzyme Commission (EC)

Table 1 : Real-time polymerase chain reaction primers for the potential biomarkers of $N$. denticulata denticulata

\begin{tabular}{|c|c|c|c|c|}
\hline Clone & Putative description & Primer name & $5 \rightarrow 3$ & bp \\
\hline CL1 & arginine kinase & $\begin{array}{l}\text { AK1-F } \\
\text { AK1-R }\end{array}$ & $\begin{array}{l}\text { CTTTGGTCTGTCCCCTGGTA } \\
\text { TTGGGATCACCAGACATGAA }\end{array}$ & 183 \\
\hline CL4 & acheron & $\begin{array}{l}\text { Aen-F } \\
\text { Aen-R }\end{array}$ & $\begin{array}{l}\text { ACGAAGTTGGAGAGGCAAGA } \\
\text { GCCTTCTTCGCTACCATCAG }\end{array}$ & 171 \\
\hline CL7 & cytochrome coxidase subunit I & $\begin{array}{l}\text { CytC-F } \\
\text { CytC-R }\end{array}$ & $\begin{array}{l}\text { CGTTCCCTCGAATGAACAAT } \\
\text { CGCCCAGAATCGAAGAAATA }\end{array}$ & 204 \\
\hline CL10 & heat shock protein 70 & $\begin{array}{l}\text { HSP70-F } \\
\text { HSP70-R }\end{array}$ & $\begin{array}{l}\text { ACTCCCAGCGTCAAGCCACCAA } \\
\text { GTCAAAATCTTCACCGCCCAAATG }\end{array}$ & 248 \\
\hline CL63 & glutathione synthetase & $\begin{array}{l}\text { GSA-F } \\
\text { GSA-R }\end{array}$ & $\begin{array}{l}\text { TTGAGTTTGGGGTTGGTGAGGTC } \\
\text { TCCGGTAGGTGATCCAGCAGTTC }\end{array}$ & 215 \\
\hline CL132 & metallothionein & $\begin{array}{l}\text { metallo-F } \\
\text { metallo-R }\end{array}$ & $\begin{array}{l}\text { CCGAAGGAGGCTGCAAGAAAAAT } \\
\text { CTCGGGTGAAGGTAAACTGG }\end{array}$ & 233 \\
\hline CL155 & methylene tetrahydrofolate reductase & $\begin{array}{l}\text { MetHydroA-F } \\
\text { MetHydroA-R }\end{array}$ & $\begin{array}{l}\text { GGATTGTCGTGCGCTTGGTATTA } \\
\text { TCCTCTCCGCTTCTCTTGTGATTG }\end{array}$ & 360 \\
\hline Sgt10 & glutathione peroxidase & $\begin{array}{l}\text { GPA-F } \\
\text { GPA-R }\end{array}$ & $\begin{array}{l}\text { GCCTGCTTCCACCACCCTGCTAAT } \\
\text { AGTAAAGTTGGGCTGGAAATCGTT }\end{array}$ & 312 \\
\hline Sgt56 & NADPH-dependent diflavinoxidoreductase 1 & $\begin{array}{l}\text { NADPH-F } \\
\text { NADPH-R }\end{array}$ & $\begin{array}{l}\text { AAAGAAGAATGGGAGCAGTTAGTG } \\
\text { CCAGGTCCTTCTTCATGTATTCTT }\end{array}$ & 274 \\
\hline Sgt108 & cathepsin L & $\begin{array}{l}\text { CatheL-F } \\
\text { CatheL-R }\end{array}$ & $\begin{array}{l}\text { TCGCCGAAGGAGATGAAAAT } \\
\text { AAGGCCGCAGGTTATGGTTG }\end{array}$ & 286 \\
\hline Sgt126 & aquaporin, isoform B & $\begin{array}{l}\text { Aquapo-F } \\
\text { Aquapo-R }\end{array}$ & $\begin{array}{l}\text { ATTATTCCGGTGGTTATTTCA } \\
\text { ATTCCTTATTCCTCCTTGGGTTTG }\end{array}$ & 199 \\
\hline Sgt145 & cathepsin A & $\begin{array}{l}\text { CathpA-F } \\
\text { CathpA-R }\end{array}$ & $\begin{array}{l}\text { AATGGTGGTCCGGGCTGTTCCT } \\
\text { TGCCGTTTCGTCATCGTTCGTG }\end{array}$ & 204 \\
\hline Sgt215 & heat shock 70 protein form 2 & $\begin{array}{l}\text { HSP70iso-F } \\
\text { HSP70iso-R }\end{array}$ & $\begin{array}{l}\text { AAGCCAGCATTGAGATAGATTCCT } \\
\text { CACAGCAGCACCATAAGCAACAG }\end{array}$ & 290 \\
\hline Sgt382 & Cu/Zn superoxide dismutase & $\begin{array}{l}\text { CuZnSOD-F } \\
\text { CuZnSOD-R }\end{array}$ & $\begin{array}{l}\text { TCGTTTTATCTGGCGGTGTTGAGG } \\
\text { CGTGACGTTCCCGATGTTCTGGT }\end{array}$ & 222 \\
\hline Sgt190 & $\beta$-actin & $\begin{array}{l}\beta \text {-actin-F } \\
\beta \text {-actin-R }\end{array}$ & $\begin{array}{l}\text { CGAGTGGCCCCCGAGGAGTC } \\
\text { TCGCAGGATGGCATGAGGGAGAG }\end{array}$ & 249 \\
\hline
\end{tabular}


numbers in the descriptions of matches with E-values less than or equal to $1 e^{-10}$.

Effect of copper exposure : To analyze expression patterns of various genes organisms were exposed to heavy metal stress, three 3 freshwater shrimps were treated with varying concentrations of copper. In brief, the environmental effects of adding copper were tested in a time-dependent $(0,1,3,6,9$ or 24 $\mathrm{hr}$ ) and dose-dependent $\left(0,1,2,5,10\right.$ or $100 \mathrm{~g} \mathrm{I}^{-1}$ for $\left.24 \mathrm{hr}\right)$ manner. The exposure concentrations of copper were chosen based on the results of previous studies (Ryu et al., 2007). The pH (8.0), salinity (28 PSU, practical salinity unit), temperature $\left(20^{\circ} \mathrm{C}\right)$ and Do concentration (>5.6 $\mathrm{mg} \mathrm{l}^{-1}, 60 \%$ saturation) were measured and maintained each day. The exposed freshwater shrimp were in a $12 \mathrm{hr}$ light $12 \mathrm{hr}$ darkness photoperiod at $20^{\circ} \mathrm{C}$. After exposure period, total RNA was extracted from the whole body of and stored at $-80^{\circ} \mathrm{C}$ prior to use.

Real-time RT-PCR analysis after copper exposure : After the shrimp underwent treatment with different concentrations of copper, gene expression pattern of putative biomarker for copper exposure in freshwater shrimp were verified by semi-quantitative

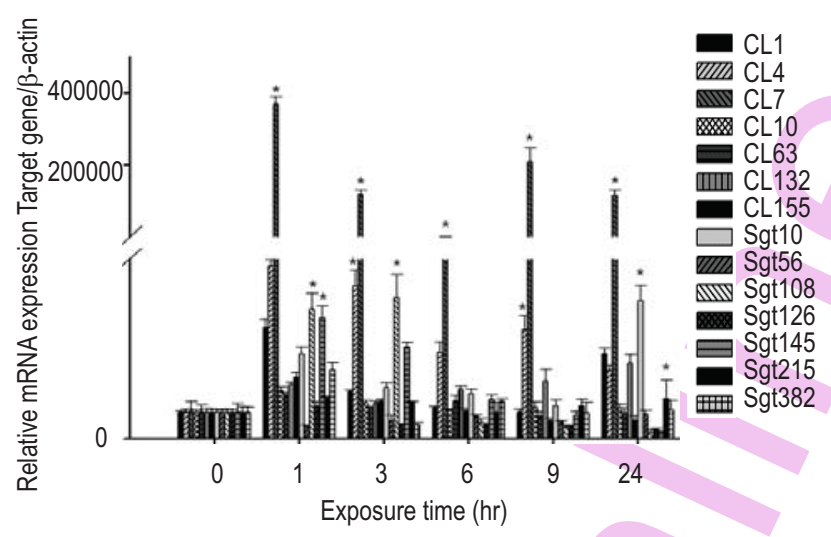

Fig. 1 : Relative mRNA expression of various genes when freshwater shrimp were exposed to copper in a time-dependent $(0,1,3,6,9$, and 24 hr) manner by real-time polymerase chain reaction analysis. Vertical error bars represent the standard error of the mean (S.E.M.) $(\mathrm{N}=3) .{ }^{*}=$ significant at $p<0.05$
RT-PCR. Specific primers for genes isolated by EST analysis were designed and used in PCR. In brief, total RNA from the shrimp with different concentrations of copper was isolated and the the pooled total RNA was used for CDNA synthesis. CDNA was synthesized from $1 \mathrm{~g}$ of total RNA using Superscript II reverse transcriptase and Oligo (dT) 20 primer (Invitrogen, USA) was used in RT-PCR. Real-time RT-PCR was performed using Fast Start SYBR Green Master Mix (Roche, USA) and $100 \mathrm{ng}$ of synthesized cDNA in a 20- $\mu$ reaction volume. Quantitative PCR was conducted using an iQ5 Multicolor Real-Time PCR instrument (Bio-Rad, USA), and normalization, $\beta$-actin gene was used as internal control. Thermal cycling conditions were 1 cycle of $3 \mathrm{~min}$ at $95^{\circ} \mathrm{C}$ (initial denaturation) followed by 40 cycles of 10 sec at $95^{\circ} \mathrm{C}, 10 \mathrm{sec}$ at $55^{\circ} \mathrm{C}$, and $20 \mathrm{sec}$ at $72^{\circ} \mathrm{C}$. All data were obtained from triplicate experiments and were presented as fluorescence relative to $\beta$-actin gene expression. The fold change in relative gene expression was determined by $2^{-\Delta c t}$ method (Giulietti et al., 2001). PCR primers for amplification of putative biomarker genes are listed in Table 1.

Statistical analysis : Data were expressed as means \pm S.D. Significant differences between the observations of control and

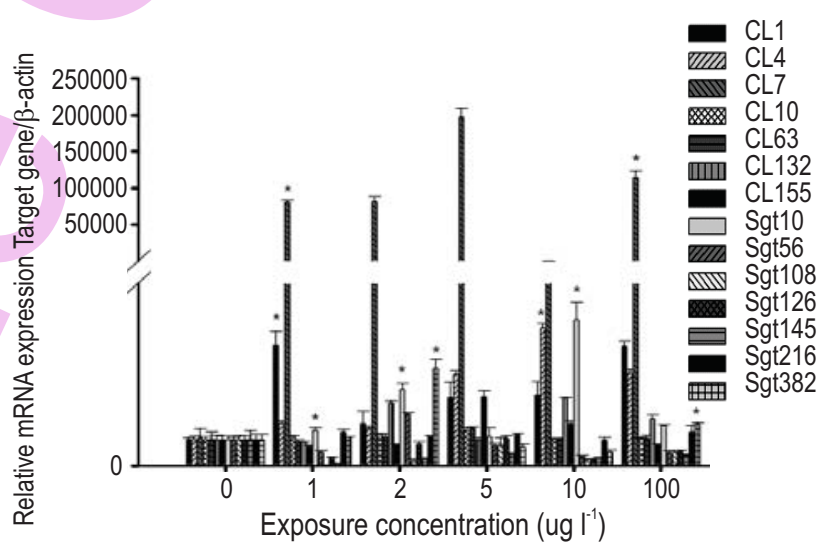

Fig. 2 : Relative mRNA expression of various genes when freshwater shrimp were exposed to copper in dose-dependent $(0,1,2,5,10$, and $100 \mu \mathrm{g} \mathrm{I}^{-1}$ for $24 \mathrm{hr}$ ) manner by real-time polymerase chain reaction analysis. Vertical error bars represent the standard error of the mean (S.E.M.) $(\mathrm{N}=3) .{ }^{*}=$ significant at $p<0.05$

Table 2: Summary of EST analysis of $N$. denticulata denticulata

\begin{tabular}{ll}
\hline Description & Number \\
\hline Total number of clones sequenced & 1,296 \\
Total number of successful sequenced & 1,247 \\
Average EST length & 695 \\
EST clusters & \\
Cluster & 185 \\
Number of unique sequenced & 603 \\
Contigs & 205 \\
Singletons & 398 \\
Significant blasthit(NCBINR database) & $319 / 1,247$ \\
\hline
\end{tabular}

${ }^{a} \mathrm{NCBI}=$ National Center for Biotechnology Information, NR = non-redundant 
Table 3 : The most abundant expressed sequence tags (ESTs) detected from the EST sequencing

\begin{tabular}{|c|c|c|c|c|}
\hline Name of cluster & No. of contigs & No. of EST & Putative description & $\%$ of Total \\
\hline CL1 & 1 & 49 & arginine kinase 1 [Macrobrachium rosenbergii] & 3.93 \\
\hline CL2 & 3 & 38 & unknown & 3.04 \\
\hline CL3 & 3 & 30 & unknown & 2.41 \\
\hline CL5 & 9 & 28 & conserved hypothetical protein [Arthroderma benhamiae CBS 112371] & 2.25 \\
\hline CL4 & 1 & 27 & acheron [Manduca sexta] & 2.17 \\
\hline CL7 & 1 & 21 & cytochrome c oxidase subunit I [Halocaridina rubra] & 1.68 \\
\hline CL6 & 3 & 18 & TPA_exp: troponin Tisoform 3 [Apismellifera] & 1.44 \\
\hline CL8 & 1 & 18 & unknown & 1.44 \\
\hline CL9 & 2 & 17 & putative ATP-dependent RNA helicase DDX17 [Acromyrmex echinatior] & 1.36 \\
\hline CL11 & 1 & 14 & ribosomal protein $\mathrm{P} 1$ [Palaemonetes varians] & 1.12 \\
\hline CL10 & 1 & 13 & heat shock protein 70 [Marsuspenaeus japonicus] & 1.04 \\
\hline CL12 & 2 & 13 & RNA polymerase I transcription factor subunit Spp27 & 1.04 \\
\hline CL13 & 1 & 12 & unknown & 0.96 \\
\hline CL14 & 3 & 12 & nesprin-1 [A. echinatior $]$ & 0.96 \\
\hline CL15 & 1 & 11 & unknown & 0.88 \\
\hline CL16 & 1 & 10 & putative $Y$ box binding protein [Pediculus humanus corporis] & 0.80 \\
\hline CL17 & 1 & 9 & arrestin [Limulus polyphemus] & 0.72 \\
\hline CL18 & 1 & 9 & putative Hrp65 protein [P. humanus corporis] & 0.72 \\
\hline CL19 & 1 & 9 & unknown & 0.72 \\
\hline CL20 & 1 & 8 & hypothetical protein [Scylla paramamosain] & 0.64 \\
\hline CL21 & 1 & 8 & myosin light chain [M. japonicus] & 0.64 \\
\hline CL22 & 1 & 8 & RNA granule protein invertebrate [Strongylocentrotus purpuratus] & 0.64 \\
\hline CL23 & 1 & 8 & hypothetical protein EAI_04489[Harpegnathos saltator] & 0.64 \\
\hline CL25 & 1 & 8 & translation initiation factor-3 [Culex quinquefasciatus] & 0.64 \\
\hline CL24 & 1 & 7 & calmodulin [Procambarus clarkii] & 0.56 \\
\hline CL26 & 1 & 7 & unknown & 0.56 \\
\hline CL30 & 1 & 7 & hypothetical protein TcasGA2_TC004915 [Tribolium castaneum] & 0.56 \\
\hline CL27 & 1 & 6 & ribosomal protein S2 [Urechis caupo] & 0.48 \\
\hline CL28 & 1 & 6 & unknown & 0.48 \\
\hline CL29 & 1 & 6 & unknown & 0.48 \\
\hline CL34 & 1 & 6 & unknown & 0.48 \\
\hline CL35 & 1 & 6 & unknown & 0.48 \\
\hline CL36 & 1 & 6 & unknown & 0.48 \\
\hline CL39 & 1 & 6 & ferritin [Macrobrachium rosenbergii] & 0.48 \\
\hline CL31 & 1 & 5 & unknown & 0.40 \\
\hline CL32 & 2 & 5 & alpha-tubulin [Eriocheir sinensis] & 0.40 \\
\hline CL40 & 1 & 5 & chromatin subfamily D member 1-like [Bombus terrestris] & 0.40 \\
\hline CL41 & 1 & 5 & serine/arginine-rich splicing factor 7-like [A. mellifera] & 0.40 \\
\hline CL42 & 1 & 5 & 60 S ribosomal protein L11 [Ascaris suum] & 0.40 \\
\hline CL43 & 1 & 5 & phosrestin-1 [Culex quinquefasciatus] & 0.40 \\
\hline CL44 & 1 & 5 & unknown & 0.40 \\
\hline CL45 & 1 & 5 & single VWC domain protein 1 [Litopenaeus vannamei] & 0.40 \\
\hline CL46 & 1 & 5 & putative Tob1 protein [P. humanus corporis] & 0.40 \\
\hline
\end{tabular}

treatment groups were analyzed using Student's paired t-test and one-way and/or multiple-comparison ANOVA followed by Tukey's test. Any difference showing $p<0.05$ was considered significant. All statistical analyses were performed using SPSS $^{\circledR}$ ver. 11.5 software (SPSS Inc., USA).

\section{Results and Discussion}

A total of 1,296 clones from the libraries of freshwater shrimp were sequenced, and 1,247 high-quality ESTs (96.2\%) were identified as being with known genes from many organisms by BLAST searches (Table 2). These pre-processed ESTs ranged from $100 \mathrm{bp}$ to $844 \mathrm{bp}$ in length, with a mean length of $695 \pm 97 \mathrm{bp}$. The clustering analysis of 1,247 ESTs yielded 603 unique sequences, of which 205 and 398 were contigs and singletons, respectively, with an average length of $726 \mathrm{bp}$ (Table 2).

The results of EST analysis of abundantly expressed genes from the freshwater shrimp $N$. denticulata denticulata is shown in Table 3, and the most abundantly expressed gene was 
Table 4 : The 30 most represented biological process, molecular function, and cellular component gene ontology (GO) terms

\begin{tabular}{|c|c|c|c|c|}
\hline & Level & GOID & GO term & No. of seqs. \\
\hline \multirow[t]{10}{*}{ Biological process } & 2 & GO:0065007 & biological regulation & 71 \\
\hline & 3 & GO:0043170 & macromolecule metabolic process & 74 \\
\hline & 4 & GO:0044260 & cellular macromolecule metabolic process & 65 \\
\hline & 4 & GO:0044249 & cellular biosynthetic process & 59 \\
\hline & 2 & GO:0008152 & metabolic process & 122 \\
\hline & 1 & GO:0008150 & biological_process & 161 \\
\hline & 3 & GO:0044237 & cellular metabolic process & 109 \\
\hline & 3 & GO:0044238 & primary metabolic process & 103 \\
\hline & 2 & GO:0009987 & cellular process & 139 \\
\hline & 3 & GO:0009058 & biosynthetic process & 60 \\
\hline \multirow[t]{10}{*}{ Molecular function } & 5 & GO:0032555 & purine ribonucleotide binding & 51 \\
\hline & 4 & GO:0032553 & ribonucleotide binding & 51 \\
\hline & 2 & G0:0003824 & catalytic activity & 112 \\
\hline & 4 & GO:0017076 & purine nucleotide binding & 52 \\
\hline & 1 & GO:0003674 & molecular_function & 223 \\
\hline & 3 & G0:0000166 & nucleotide binding & 68 \\
\hline & 3 & GO:0016787 & hydrolase activity & 49 \\
\hline & 3 & GO:0005515 & protein binding & 91 \\
\hline & 3 & GO:0003676 & nucleic acid binding & 50 \\
\hline & 2 & GO:0005488 & binding & 186 \\
\hline \multirow[t]{10}{*}{ Cellular component } & 2 & GO:0005623 & cell & 150 \\
\hline & 6 & GO:0043231 & intracellular membrane-bounded organelle & 68 \\
\hline & 3 & GO:0044464 & cell part & 150 \\
\hline & 3 & G0:0043227 & membrane-bounded organelle & 68 \\
\hline & 4 & GO:0044424 & intracellular part & 119 \\
\hline & 5 & GO:0005737 & cytoplasm & 86 \\
\hline & 4 & GO:0005622 & intracellular & 122 \\
\hline & 5 & GO:0043229 & intracellular organelle & 99 \\
\hline & 1 & G0:0005575 & cellular_component & 157 \\
\hline & 2 & GO:0043226 & organelle & 99 \\
\hline
\end{tabular}

CL1 $(3.9 \%)$ of all sequenced ESTs. BLASTX searches indicated that this transcript was most similar to anarginine kinase- 1 protein from freshwater shrimp, Macrobrachium rosenbergii (179E-173). The gene encoding arginine kinase-1 (AK-1, CL1 contig) was of particular interest because this enzyme is thought to play an important role in the coupling of energy production and utilization and the immune response in shrimp (Arockiaraj et al., 2011). Recent studies have suggested that arginine kinase might play an important role in many biological events in crustaceans. For example, expression of arginine kinase was correlated closely with hypoxic stress in M. japonicas (Abe et al., 2007), exposure to lead in yabby, Cherax destructor (Morris et al., 2005), and acclimation to cadmium in crab, Eriocheir sinensis (Silvestre et al., 2006).

The unique sequences were compared to annotations by Gene Ontology analysis using the automated software Blast2GO (Conesa et al., 2005). GO terms were obtained for 412 unique sequences, including, 146 contigs and 266 singletons. The 30 most highly represented $\mathrm{GO}$ terms are shown in Table 4.

In fish, copper toxicity, is one of the most common heavy metal toxicity conditions and is primarily related to structural damage in gills. However, in crustaceans including shrimp, the physiological effect of copper toxicity is not as clearly understood (Wilson and Taylor, 1993). To study the potential biomarkers for heavy metal exposure and toxic effect of exposure to metal ions in freshwater in vertebrate, $N$. denticulata denticulata were exposed to copper of varying concentrations for varying lengths of time.

As shown in Fig. 1 and 2, the expression levels of 14 transcripts varied according to the individuals' exposure to copper in a time-and concentration-dependent manners. A total of 9 putative biomarker genes for heavy metal exposure, including CL1 (arginine kinase), CL4 (acheron), CL7 (cytochrome c oxidase subunit I), CL132 (metallothionein), CL155 (methylene tetrahydrofolate reductase), Sgt10 (glutathione peroxidase), Sgt108 (cathepsin L), Sgt145 (cathepsin A) and Sgt382(Cu/Zn superoxide dismutase) transcripts were significantly increased (over 2-fold) at periods ranging from 1-24 hr post exposure, in a time-and/or dose-dependent manner.

Hence, on the basis of observations it may be concluded that nine potential biomarkers including arginine kinase, acheron, cytochrome c oxidase subunit I, metallothionein, methylene 
tetrahydrofolate reductase, glutathione peroxidase, cathepsin L, cathepsin A and Cu/Zn superoxide dismutase genes are potential biomonitoring markers of heavy metal pollution which have different toxicity mechanisms and ecological effects in nature.

\section{Acknowledgment}

This research was supported by a grant from the National Institute of Fisheries Science (R2016068)

\section{References}

Abe, H., S. Hirai and S. Okada: Metabolic responses and arginine kinase expression under hypoxic stress of the kuruma prawn Marsupenaeus japonicas. Comp. Biochem. Physiol. Part A, 146, 40-46 (2007).

Aniello, F., A. Locascio, L. Fucci, G. Geraci and M. Branno: Isolation of cDNA clones encoding DNA methyltransferase of sea urchin $P$. lividus: Expression during embryonic development. Gene, 178, 57-61 (1996).

Arockiaraj, J., P. Vanaraja, S. Easwvaran, A. Singh, T. Alinejaid, R.Y. Othma and S. Bhassu: Gene profiling and characterization of arginine kinase-1 (MrAK-1) from freshwater giant prawn (Macrobrachium rosenbergii). Fish. Shellfish. Immunol., 31, 81-89 (2011).

Arun Kumar, K. and H. Achyuthan: Heavy metal accumulation in certain marine animals along the East Coast of Chennai, Tamil Nadu, India. J. Environ. Biol., 28, 637-643 (2007).

Auslander, M., Y. Yudkovski, V. Chalifa-Caspi, B. Herut, R. Ophir, R. Reinhardt, P. M. Neumann and M. Tom: Pollution-affected fish hepatic transcriptome and its expression patterns on exposure to cadmium. Mar. Biotechnol., 10, 250-261 (2008).

Bidwell, J.R. and J.R. Gorrie: The influence of salinity on metal uptake and effects in the midge Chironomus maddeni. Environ. Pollut., 139, 206-213 (2006).

Calzolai, L., W. Ansorge, E. Calabrese, N. Denslow, P. Part and T. Lettieri: Transcriptomics and proteomics. Applications to ecotoxicology. Comp. Biochem. Physiol. Part D Genom. Proteom., 2, 245-249 (2007).

Chamberlain, G.W.: Sustainability of world shrimp farming global trends: Fisheries Management (Eds.: E. Pikitch, D.D. Huppert and M. Sissenwine), American Fisheries Society Symposium 20, Bethesda, Maryland, pp. 195-209 (1997).

Conesa, A., S. Götz, J.M. Garcia-Gomez, J. Terol, M. Talon and M. Robles: Blast2GO: A universal tool for annotation, visualization and analysis in functional genomics research. Bioinformatics, 21, 3674-3676 (2005).

Cornu, J.Y., D. Huguenot, K. Jézéquel, M. Lollier and T. Lebeau: Bioremediation of copper-contaminated soils by bacteria. World J. Microbiol. Biotechnol., 33, (DOI: https://doi.org/10.1007/s11274016-2191-4) (2017).

Ewing, B. and P. Green: Base-calling of automated sequencer traces using phred. II. Error probabilities. Genome. Res., 8, 186-194 (1998).

Garnacho, E., P.A. Tyler and L.S. Peck: Reproduction, seasonality, and copper toxicity in the coastal mysid Praunus flexuosus. J. Mar. Biol. Ass. U. K., 81, 433-440 (2001).

Giulietti, A., L. Overbergh, D. Valckx, B. Decallonne, R. Bouillon and C.
Mathieu: An overview of real-time quantitative PCR: Applications to quantify cytokine gene expression. Methods, 25, 386-401 (2001).

Bradl, H.: Heavy metals in the environment: Origin, Interaction and Remediation, $1^{\text {st }}$ Edn., Academic Press, 2005.

Huang, $X$. and A. Madan: CAP3: A DNA sequence assembly program. Genome. Res., 9, 868-877(1999).

IPCS: Environmental Health Criteria 200: Copper. World Health Organization, Geneva, (1998).

Lightner, D.V.: A handbook of shrimp pathology and diagnostic procedures for diseases of cultured penaeid shrimp. World Aquaculture Society, Baton Rouge, LA, p. 304 (1996).

Lodhi, H.S., M.A. Khan, R.S. Verma and U.D. Sharma: Acute toxicity of copper sulphate to fresh water prawns. J. Environ. Biol., 27, 585588 (2006).

Martin, S.A., S.C. Blaney, D.F. Houlihan and C.J. Secombes: Transcriptome response following administration of a live bacterial vaccine in Atlantic salmon (Salmo salar). Mol. Immunol., 43, 19001911 (2006).

Morris, S., W.J. van Aardt and M.D. Ahern: The effect of lead on the metabolic and energetic status of the Yabby, Cherax destructor, during environmental hypoxia. Aquat. Toxicol., 75, 16-31 (2005).

Munari, C. and M. Mistri: Effect of copper on the scope for growth of clams (Tapes philippinarum) from a farming area in the Northern Adriatic Sea. Mar. Environ. Res., 64, 347-357 (2007).

Mykles, D.L. and J.H. Hui: Neocaridina denticulata: A decapod crustacean model for functional genomics. Integr. Comp. Biol., 55, 891-897 (2015).

Pertea, G., X. Huang, F. Liang, V. Antonescu, R. Sultana, S. Karamycheva, Y. Lee, J. White, F. Cheung, B. Parvizi, J. Tsai and J. Quackenbush: TIGR gene indices clustering tools (TGICL): A software system for fast clustering of large EST datasets. Bioinformatics, 19, 651-652 (2003).

Reichelt-Brushett, A.J. and K.M. Wagner: Effects of copper on the fertilization success of the soft coral Lobophytum compactum. Aquat. Toxicol., 74, 280-284 (2005).

Ryu, J.S., E.K. Kim, Y.R. Moon, H.M. Kim, H.J. Kim and K.H. Choi: Acute toxicity test of heavy metals using Koreans freshwater shrimp, Neocardina denticulate. J. Environ. Toxicol., 22, 171-175 (2007).

Schneider, M., L. Lane, E. Boutet, D. Lieberherr, M. Tognolli, L. Bougueleret and A. Bairoch: The UniProtKB/Swiss-Prot knowledgebase and its plant proteome annotation program. $\mathrm{J}$. Proteomics, 72, 567-573 (2009).

Silvestre, F., J.F. Dierick, C. Dumont, M. Dieu, M. Raes and P. Devos: Differential protein expression profiles in anterior gills of Eriocheir sinensis during acclimation to cadmium. Aquat. Toxicol., 76, 46-58 (2006).

Stohs, S.J. and D. Bagchi: Oxidative mechanisms in the toxicity of metal ions. Free. Radic. Biol. Med., 18, 321-336 (1995).

Wang, C., F. Zhang, W. Cao and J. Wang: The identification of metallothionein in rare minnow (Gobiocypris rarus) and its expression following heavy metal exposure. Environ. Toxicol. Pharmacol., 37, 1283-1291 (2014).

Wilson, R.W. and W.W. Taylor: The physiological responses of freshwater rainbow trout, Onchorhynchus mykiss, during acutely lethal copper exposure. J. Comp. Physiol. B., 163, 38-47 (1993).

Wright, D.A.: Trace metal uptake and sodium regulation in Gammarus marinus from metal-polluted estuaries in England. J. Mar. Biol. Assoc. U.K., 12, 83-92 (1986). 